\title{
Increased hedonic differences despite increases in hedonic range
}

\author{
Debra A. Zellner, Ke'Nesha Jones, Jennifer Morino, \\ Elizabeth S. Cogan, ANd Emily M. Jennings \\ Montclair State University, Montclair, New Jersey \\ AND \\ SCOTT PARKer \\ American University, Washington, DC
}

\begin{abstract}
Viewing hedonically negative paintings increased the hedonic ratings of subsequently viewed test paintings (positive hedonic contrast; Experiment 1) and also increased the degree of preference between the test paintings (Experiments 2 and 3). This result differs from the reduction in hedonic preference (hedonic condensation) that accompanies negative hedonic contrast. It also differs from the reduction in perceived differences that usually accompanies expansion of stimulus range and that is predicted by numerous theories.
\end{abstract}

Studies of hedonic or affective response to a stimulus usually assess either the degree of liking for the stimulus or the preference for one stimulus over another. Although some people use the terms liking and preference interchangeably (see Rozin \& Zellner, 1985, for a discussion), the words refer to different things. Liking reflects the hedonic value of a single particular item. Preference, on the other hand, is a comparative judgment. It is the difference in the degree to which two or more things are liked. So, for example, a person might like the flavor of apples but prefer the flavor of pears to that of apples.

Although liking ratings and preference ratings involve different kinds of judgments, they both appear to be affected by a particular kind of change in stimulus context. When positive context stimuli are presented before a set of more hedonically neutral test stimuli, both negative hedonic contrast (Parker, Bascom, Rabinovitz, \& Zellner, 2008; Rota \& Zellner, 2007; Zellner, Rohm, Bassetti, \& Parker, 2003) and a decrease in preference between test stimuli (i.e., hedonic condensation) occur (Zellner, Allen, Henley, \& Parker, 2006; Zellner, Mattingly, \& Parker, 2009). So negative hedonic contrast and hedonic condensation cooccur when good stimuli precede less good stimuli.

Why does hedonic condensation occur, and why does it occur under situations that also result in negative hedonic contrast? One possibility is focused on the presentation of context stimuli before the stimuli that undergo condensation and negative hedonic contrast. These context stimuli are, in these studies, distinctly more hedonically positive than are the test stimuli. Therefore, the full hedonic range experienced by the subjects is greater when the context stimuli are present than when they are not.
Numerous theories predict negative hedonic contrast with the addition of more hedonically positive context stimuli (see, e.g., Helson, 1964; Parducci, 1965, 1968). More important for the present purposes, there are also many theories (e.g., Durlach \& Braida, 1969; Gravetter \& Lockhead, 1973; Lockhead \& Hinson, 1986; Luce, Green, \& Weber, 1976; Parducci, 1995; Petzold, 1990; Sarris, 2006; Wedell, 2008) predicting that expanding the perceptual range of stimuli will result in reduced discriminability or difference between any pair of stimuli within the range (see, e.g., Ward, Armstrong, \& Golestani, 1996, for some examples and a thorough discussion of the issues). So one might expect that condensation should accompany contrast - that expansion of the hedonic range with hedonically positive or negative context stimuli should result in a reduction of preference between the test stimuli.

The only one of these theories that has been directly applied to hedonic ratings is Parducci's range-frequency theory (Parducci, 1965, 1995). It predicts that hedonically negative context stimuli preceding pairs of more neutral test stimuli should result in hedonic condensation, much as hedonically positive context stimuli do (as in Zellner et al., 2006; Zellner et al., 2009). According to rangefrequency theory, expanding the stimulus range will decrease perceived differences between stimuli (Wedell, Hicklin, \& Smarandescu, 2007). Subjects who encounter context stimuli (whether hedonically positive or negative) prior to more neutral test stimuli will experience a larger hedonic range than will subjects who encounter only the test stimuli. This should result in smaller hedonic differences between the test stimuli. Hence, preference magnitudes should be smaller (i.e., hedonic condensation should

D. A. Zellner, zellnerd@mail.montclair.edu 
Table 1

Effects of Relation of Context to Test Stimuli on Liking and Preference

\begin{tabular}{llc}
\hline & \multicolumn{1}{c}{ Context Stimuli More } & Context Stimuli More \\
& Positive Than Test Stimuli & Negative Than Test Stimuli \\
\hline Liking & Negative hedonic contrast & Positive hedonic contrast \\
Preference & Hedonic condensation & $? ? ?$ \\
\hline
\end{tabular}

occur) for subjects whose hedonic ranges are extended in either direction (positive or negative). And condensation is indeed what we have found when the preliminary context stimuli are more hedonically positive than the test stimuli.

But what happens to preference when the preliminary context stimuli are relatively hedonically negative, a situation that produces positive hedonic contrast? Although positive hedonic contrast (an increase in liking of stimuli following hedonically negative context stimuli) has been demonstrated (Dolese, Zellner, Vasserman, \& Parker, 2005; Parker et al., 2008), there have been no investigations of accompanying preference change. In this study, we investigate preference changes that accompany positive hedonic contrast, resulting from hedonically negative context stimuli using stimuli similar to those used by Dolese et al. The present state of our knowledge is summarized in Table 1 . The present experiments were designed to determine whether hedonic condensation accompanies positive hedonic contrast as it does negative hedonic contrast.

Because some stimuli were new to this investigation, in Experiment 1 we determined whether positive hedonic contrast occurred using the new stimulus sets. In Experiment 2, we investigated changes in preference due to context. In Experiment 3, we further investigated the effect of hedonically negative context stimuli on preference, eliminating the possibility that the effect might result from a rating bias.

\section{EXPERIMENT 1}

Dolese et al. (2005) found positive hedonic contrast when subjects rated five hedonically negative context stimuli (paintings from Francisco Goya's Dark Period) prior to rating two slightly hedonically pleasant test stimuli (pastoral works by Goya). In the present study, we attempt to replicate that finding using only four of the Dark Period paintings as context stimuli, followed by four of Goya's pastoral paintings as test stimuli.

\section{Method}

Subjects. Twenty-eight Montclair State University undergraduate students from the psychology department subject pool ( 7 male and 21 female; mean age $=21$ years) served as subjects. The subjects were tested individually.

Stimuli. The stimuli were color pictures of paintings cut out of art books and pasted on individual $28 \times 17.5 \mathrm{~cm}$ sheets of white cardboard. The paintings were eight works by Goya from two distinctly different periods. The four test paintings were slightly hedonically pleasant pastoral paintings. They were The Swing, The Vintage, The Washer Women, and The Crockery Seller. The four context paintings were hedonically unpleasant paintings from Goya's Dark Period.
They were The Incantation, The Great He-Goat, a section of Old Men Eating Soup, and a section of Pilgrimage of San Isidro.

Procedure. The 28 subjects were randomly assigned to one of two groups: Group C (context group) and Group N (no-context group). The subjects in Group $\mathrm{C}$ were asked to look at and rate the four Dark Period paintings (context paintings), followed by the four pastoral paintings (test paintings). The subjects in Group N viewed and rated only the four pastoral (test) paintings.

The subjects rated how much they liked each picture by using a 201-point bipolar hedonic scale. A rating of -100 indicated that the subject found the picture to be the most unattractive imaginable; 0 indicated that the subject neither liked nor disliked it; and +100 meant that the subject found the picture the most attractive imaginable. The subjects were asked to rate each picture on the basis of how much they would like to hang it on a wall in their home. They viewed and rated the pictures one at a time. The pictures were presented in a variety of random orders.

\section{Results}

We calculated each subject's average rating for the four test paintings, as well as the average rating given to the four context paintings by the Group $\mathrm{C}$ subjects. The subjects in Group $\mathrm{C}$ rated the context paintings from Goya's Dark Period as unattractive $(M=-34.3, S D=26.9)$. Group $\mathrm{C}$ rated the pastoral test pictures $(M=47.0, S D=$ 23.2) as significantly more attractive than did Group $\mathrm{N}$ $(M=20.9, S D=24.6)[t(26)=2.89, p=.008$; estimated $\left.\omega^{2}=.21\right]$.

\section{Discussion}

Like Dolese et al. (2005), we found positive hedonic contrast when hedonically negative paintings preceded slightly hedonically positive test paintings. The test stimuli were rated as more hedonically positive when preceded by the hedonically negative stimuli than when presented alone.

\section{EXPERIMENT 2}

Using the stimuli that produced positive hedonic contrast in Experiment 1, we investigated whether condensation accompanies positive hedonic contrast as it does negative hedonic contrast (Zellner et al., 2006).

\section{Method}

Subjects. Forty Montclair State University undergraduate students from the psychology department subject pool ( 8 male and 32 female; mean age $=19$ years) served as subjects. The subjects were tested individually.

Stimuli. The stimuli were the same color pictures of paintings used in Experiment 1.

Procedure. Two groups of subjects were shown two pairs of slightly hedonically positive pastoral paintings by Goya (the test pairs). These four paintings were the ones used as test stimuli in Experiment 1 . The paintings were paired on the basis of the data of Experiment 1, with the differences in mean hedonic ratings of the two paintings within a pair as similar as possible for the two pairs. Both groups were asked to report, for each pair, if they preferred one of the paintings to the other, and if so, how much more they liked the preferred one on a 10 -point scale $(1$, slightly more; 10 , extremely more). If they did not have a preference, a 0 rating was recorded. The Group C subjects rated their preferences immediately after first viewing and giving preference ratings for two pairs of paintings from Goya's Dark Period (the context pairs). These four paintings were the 
ones used as context stimuli in Experiment 1 and were paired up on the same basis as were the test stimuli. The Group N subjects viewed and rated only the two pairs of pastoral test paintings.

The two possible orders of the context pairs and those of the two test pairs were used equally often and completely crossed. Within a pair, the paintings were randomly assigned to presentation on the right or the left.

\section{Results}

We calculated each subject's average preference rating for the two pairs of test paintings, as well as the average preference rating for the two pairs of context paintings by the Group C subjects. There was a significant difference between the groups' mean preference ratings for the two pairs of test paintings (pastoral paintings) $[t(38)=2.17$, $p<.04$; estimated $\omega^{2}=.09$ ]. The data appear in Table 2 . The Group C subjects reported a greater preference for one test painting over the other $(M=4.8, S D=1.8)$ than did the Group N subjects $(M=3.4, S D=2.1)$. The Group $\mathrm{C}$ subjects preferred one context stimulus $(M=$ $3.4, S D=1.9$ ) over the other about as much as Group $\mathrm{N}$ preferred one test stimulus over the other.

\section{Discussion}

The findings were the opposite of condensation, the reduction in preference found in circumstances that produce negative hedonic contrast (Zellner et al., 2006; Zellner et al., 2009). Instead, in conditions that induce positive hedonic contrast, preference between the test paintings increased rather than decreased.

This increase in preference is surely contrary to rangefrequency theory and to several other theories as well, as will be discussed later. For this reason, it seems useful to consider whether the result might not be what it appears, but rather some by-product of Group C but not Group N rating their preferences between the context paintings before rating their preferences between the test paintings. Those initial ratings might have engendered some biases in number use that might have contributed to the increases in preference ratings found here (see, e.g., Poulton, 1977, and Poulton, 1989, Chapter 9).

One possible bias could result from Group C's use of the 10-point preference scale to rate the two pairs of context stimuli prior to rating the test stimuli. Group C, unlike Group N, had used up some numbers on the scale and might have felt a need to rate the test stimuli differently.

Table 2

Means and Standard Deviations of Preference Ratings for All Stimuli in Experiments 2 and 3

\begin{tabular}{|c|c|c|c|c|}
\hline \multirow[b]{2}{*}{ Group } & \multicolumn{2}{|c|}{$\begin{array}{l}\text { Context } \\
\text { Paintings }\end{array}$} & \multicolumn{2}{|c|}{ Test Paintings } \\
\hline & $M$ & $S D$ & $M$ & $S D$ \\
\hline \multicolumn{5}{|c|}{ Experiment 2} \\
\hline $\mathrm{C}$ & 3.4 & 1.9 & 4.8 & 1.8 \\
\hline $\mathrm{N}$ & & & 3.4 & 2.1 \\
\hline \multicolumn{5}{|c|}{ Experiment 3} \\
\hline Negative & & & 5.3 & 1.5 \\
\hline Control & & & 4.0 & 1.6 \\
\hline
\end{tabular}

Note-C, context; N, no context.
They might have then given the test stimuli slightly larger ratings (closer to the middle of the scale) in an effort to vary their ratings and to use more of the scale. This sort of process is predicted by the range-frequency theory of Parducci (1965). It would result in the two groups' using different numbers on the scale even though they did not perceive the degree of preference between the test stimuli differently. The fact that Group $\mathrm{N}$ rated the preference between the test stimuli the same as Group $\mathrm{C}$ rated their preference between the context stimuli (both means of 3.4; see Table 2) suggests that this might be the case. If it is, the effect that we found in this experiment is the result of a tendency of the subjects to distribute their ratings across the response range rather than of any shift in actual preference.

\section{EXPERIMENT 3}

In order to eliminate the possibility that giving preference ratings for the context pairs of paintings affected the preference ratings given to the test paintings, we had subjects simply view the context paintings and hear descriptions of them without making any ratings. The subjects made numerical preference ratings only for the test pairs. This sort of procedure has sufficed to produce contrast in judgments of dot numerosity (Helson \& Kozaki, 1968), judgments of faces (Rutherford, Chattha, \& Krysko, 2008), and judgments of flavor hedonics (Stevenson, Tomiczek, \& Oaten, 2007). Indeed, Parducci and Wedell (1990) discussed the fact that even context stimuli encountered outside the laboratory can influence subjects' judgments.

Another new feature of Experiment 3 is that all of the subjects saw the same number of paintings. We know that hedonic contrast can be demonstrated not only when the comparison group (Group $\mathrm{N}$ in Experiment 1) sees no context stimuli at all, but also when the comparison group sees context stimuli hedonically equivalent to the test stimuli (Zellner et al., 2003). So in Experiment 3, some subjects saw unattractive context paintings (as did Group $\mathrm{C}$ in Experiment 2), and others saw just as many context paintings, similar in hedonic value to the test paintings.

\section{Method}

Subjects. Thirty-four Montclair State University undergraduate students from the psychology department subject pool (16 male and 18 female; mean age $=19$ years) participated. The subjects were tested individually.

Stimuli. The stimuli were color pictures of paintings cut out of art books pasted on individual $28 \times 17.5 \mathrm{~cm}$ sheets of white cardboard The paintings were 12 works by Goya. There were two sets of four context paintings and one set of four test paintings. One set of context paintings consisted of the same hedonically negative Dark Period paintings used in Experiment 2 (hereafter called the negative context paintings). The other set of four context paintings (The Marquesa de Pontejos, The Milkmaid of Bordeaux, The Blind Man's Bluff, and The Parasol, hereafter called the control context paintings) were rated as slightly positive in a pilot study $(M=16.4, S D=32.5$, on the 201point bipolar hedonic scale used in Experiment 1). Note that their mean rating $(M=16.4)$ was almost equal to that of the test stimuli by Group N in Experiment $1(M=20.9)$. Therefore, we should expect little contrast for the subjects first shown these context stimuli. The 
two sets of context paintings (negative and control) provide the only procedural difference between the two groups of subjects. The test paintings for both groups were the four slightly hedonically positive paintings used as test paintings in Experiments 1 and 2.

Procedure. The 34 subjects were randomly assigned to one of two groups: Group Control and Group Negative. The subjects in Group Control were asked to look at the four control context paintings one at a time and were given a brief description of each painting.

The subjects in Group Negative were asked to view the negative context paintings used previously and were given similar descriptions of the paintings. The subjects in both groups were told that all of the paintings were by Goya.

After viewing the context paintings, all of the subjects were shown the two pairs of test paintings used in Experiment 2 and told that these were some additional paintings by Goya. They were asked whether they preferred one member of the pair over the other, and if so, how much more they liked it, using the same 10-point scale that was used in Experiment 2.

The context paintings were presented to the subjects in random order. The test pairs were shown equally often in the two possible orders. Within a test pair, the paintings were assigned to presentation on the right or left at random.

\section{Results}

We calculated each subject's average preference rating for the two pairs of test paintings. Their means are shown in Table 2. The groups' mean preference ratings for the two pairs of test paintings differed significantly $[t(32)=$ $2.48, p<.02$; estimated $\omega^{2}=.13$ ]. Group Negative subjects reported a greater preference for one test painting over the other $(M=5.3, S D=1.5)$ than did Group Control subjects $(M=4.0, S D=1.6)$.

\section{Discussion}

Experiment 3 confirms the finding in Experiment 2. Situations that produce positive hedonic contrast also give rise to enhanced preferences among the test stimuli. Those stimuli's hedonic values are both elevated (contrast) and spread out (increased preference). This result does not depend on the subjects' making ratings of the less-good context stimuli or on the number of stimuli that the subjects see prior to rating the test stimuli (Experiment 2 vs. 3). It therefore appears that the effect is an actual increase in the degree of preference as a result of viewing hedonically negative stimuli.

\section{GENERAL DISCUSSION}

In Experiment 1, prior exposure to a set of four hedonically negative context paintings resulted in positive hedonic contrast - an increase in the hedonic evaluation of the test paintings similar to that seen in previous studies (e.g., Dolese et al., 2005; Parker et al., 2008). Prior exposure to these same hedonically negative context paintings also resulted in an increase in the degree of preference between the pairs of these test paintings (Experiments 2 and 3). This enhanced preference is the opposite of what is seen when test stimuli follow more hedonically positive context stimuli (Zellner et al., 2006; Zellner et al., 2009).

Although in the present study, the context stimuli are hedonically negative and the test stimuli are slightly hedonically positive, we do not think that is a critical source of our results. Positive hedonic contrast occurs when both the context and the test stimuli are hedonically positive, if the test stimuli are better liked than the context stimuli (Parker et al., 2008), and we think that any situation giving rise to positive hedonic contrast will also result in an increase in preference magnitude.

This enhanced preference is a novel result that has not been previously demonstrated in hedonic judgments or with any other type of stimulus judgments and is contrary to what is predicted by range-frequency models. Rangefrequency theory (Parducci, 1965, 1995; see also Mellers $\&$ Cooke, 1994) and some other theories (see Petzold, 1990, and Sarris, 2006) all predict a reduction in perceived difference between a fixed pair of stimuli as the stimulus range increases, but we found an increase. Therefore, our finding offers no support for these theories.

What, then, accounts for our results? One possibility that we considered concerns the magnitude of the preferences. We have, like most people, discussed contrast as a phenomenon that alters the magnitudes of stimuli along some dimension - in our case, hedonic value. But perceived differences between stimuli are themselves quantities that have magnitudes. Perhaps differences undergo contrast. If so, small differences might render large differences even larger, much as less-good stimuli render good stimuli even better. If that sort of thing happens, could it account for our results?

The relevant data come from Experiment 2. In that experiment, the subjects in Group $\mathrm{C}$ gave preference ratings for the hedonically negative context paintings before rating the hedonically positive test paintings, whereas Group N rated only the test paintings. Suppose that Group C's preferences between the context paintings were small, relative to Group N's preferences between the test paintings. Then Group C would have seen small differences before large differences, and contrast would make those large differences seem even larger. That would account for our discovery that Group $\mathrm{C}$ had greater preferences among the test paintings than did Group N.

However, inspection of Table 2 provides no evidence that any such thing occurred in Experiment 2. Group C's preference ratings for the context paintings $(M=3.4, S D=1.9)$ have essentially the same distribution as Group N's preference ratings for the test paintings $(M=3.4, S D=2.1)$. So far as can be seen, the magnitudes of hedonic differences for the context paintings and the precontrast magnitudes of hedonic differences for the test paintings were virtually identical. The idea that contrast might occur for differences much as it does for single-stimulus magnitudes is an interesting one, but no such process can account for our data.

Whatever the mechanism causing this effect proves to be, extending the range by adding context stimuli both produced positive hedonic contrast and enhanced perceived differences. For the moment, this combination of effects is unique to the study of hedonics and has no explanation.

\section{AUTHOR NOTE}

We thank Martha Teghtsoonian, Lawrence Ward, and an anonymous reviewer for helpful comments on earlier versions of the manuscript. 
Correspondence concerning this article should be addressed to D. A. Zellner, Department of Psychology, Montclair State University, Montclair, NJ 07043 (e-mail: zellnerd@mail.montclair.edu).

\section{REFERENCES}

Dolese, M. J., Zellner, D. A., Vasserman, M., \& Parker, S. (2005). Categorization affects hedonic contrast in the visual arts. Bulletin of Psychology \& the Arts, 5, 21-25.

DuRLACH, N. I., \& BRAIDA, L. D. (1969). Intensity perception: I. Preliminary theory of intensity resolution. Journal of the Acoustical Society of America, 46, 372-383.

Gravetter, F., \& Lockhead, G. R. (1973). Criterial range as a frame of reference for stimulus judgments. Psychological Review, 80, 203216.

Helson, H. (1964). Adaptation-level theory. New York: Harper \& Row.

Helson, H., \& KozaKi, A. (1968). Anchor effects using numerical estimates of simple dot patterns. Perception \& Psychophysics, 4, 163-164.

Lockhead, G. R., \& Hinson, J. (1986). Range and sequence effects in judgment. Perception \& Psychophysics, 40, 53-61.

Luce, R. D., Green, D. M., \& Weber, D. L. (1976). Attention bands in absolute identification. Perception \& Psychophysics, 20, 49-54.

Mellers, B. A., \& Cooke, A. D. J. (1994). Trade-offs depend on attribute range. Journal of Experimental Psychology: Human Perception \& Performance, 20, 1055-1067.

PARDuCCI, A. (1965). Category judgment: A range-frequency model. Psychological Review, 72, 407-418.

PARDUCCI, A. (1968). The relativism of absolute judgments. Scientific American, 219, 84-90.

Parducci, A. (1995). Happiness, pleasure, and judgment: The contextual theory and its applications. Mahwah, NJ: Erlbaum.

PARduCCI, A., \& Wedell, D. H. (1990). The context for evaluative judgments: Psychophysics and beyond. In H.-G. Geissler, M. H. Muller, \& W. Prinz (Eds.), Psychophysical explorations of mental structures (pp. 94-103). Lewiston, NY: Hogrefe \& Huber.

Parker, S., Bascom, J., Rabinovitz, B., \& Zellner, D. [A.] (2008). Positive and negative hedonic contrast with musical stimuli. Psychology of Aesthetics, Creativity, \& the Arts, 2, 171-174.

Petzold, P. (1990). The influence of anchor stimuli on judgments of attributes. In H.-G. Geissler, M. H. Muller, \& W. Prinz (Eds.), Psychophysical explorations of mental structures (pp. 138-146). Lewiston, NY: Hogrefe \& Huber.

Poulton, E. C. (1977). Quantitative subjective assessments are almost always biased, sometimes completely misleading. British Journal of Psychology, 68, 409-425.

Poulton, E. C. (1989). Bias in quantifying judgments. Hillsdale, NJ: Erlbaum.

Rota, L. M., \& Zellner, D. A. (2007). The categorization effect in hedonic contrast: Experts differ from novices. Psychonomic Bulletin \& Review, 14, 179-183.

Rozin, P., \& Zellner, D. A. (1985). The role of Pavlovian conditioning in the acquisition of food likes and dislikes. In N. S. Braveman \& P. Bronstein (Eds.), Experimental assessments and clinical applications of conditional food aversions (Annals of the New York Academy of Sciences, Vol. 443, pp. 189-202). New York: New York Academy of Sciences.

Rutherford, M. D., Chattha, M. H., \& Krysko, K. M. (2008). The use of aftereffects in the study of relationships among emotion categories. Journal of Experimental Psychology: Human Perception \& Performance, 34, 27-40.

SARRIS, V. (2006). Relational psychophysics in humans and animals: A comparative-developmental approach. New York: Psychology Press.

Stevenson, R. J., Tomiczek, C., \& OAten, M. (2007). Olfactory hedonic context affects both self-report and behavioural indices of palatability. Perception, 36, 1698-1708.

Ward, L. M., Armstrong, J., \& Golestani, N. (1996). Intensity resolution and subjective magnitude in psychophysical scaling. Perception \& Psychophysics, 58, 793-801.

WedELL, D. H. (2008). A similarity-based range-frequency model for two-category rating data. Psychonomic Bulletin \& Review, 15, 638643.

Wedell, D. H., Hicklin, S. K., \& Smarandescu, L. O. (2007). Contrasting models of assimilation and contrast. In D. A. Stapel \& J. Suls (Eds.), Assimilation and contrast in social psychology (pp. 45-74). New York: Psychology Press.

Zellner, D. A., Allen, D., Henley, M., \& Parker, S. (2006). Contrast makes little difference: Good stimuli make mediocre stimuli less good and less different. Psychonomic Bulletin \& Review, 13, 235-239.

Zellner, D. A., Mattingly, M. C., \& Parker, S. (2009). Categorization reduces the effect of context on hedonic preference. Attention, Perception, \& Psychophysics, 71, 1228-1232.

Zellner, D. A., Rohm, E. A., Bassetti, T. L., \& Parker, S. (2003). Compared to what? Effects of categorization on hedonic contrast. Psychonomic Bulletin \& Review, 10, 468-473.

(Manuscript received July 15, 2009; revision accepted for publication February 6, 2010.) 